\title{
Association of halitosis with dental caries in pediatric patients in a tertiary level hospital
}

\author{
Nazia Mehanaz, Helal Uddin, Ashis Kumar Biswas, Suvasish Das, Shahriar Mohd Shams, Qazi \\ Tanzin Ahmed, Arup Kumar Saha, Abu Nasher Mohammad Badrudduza
}

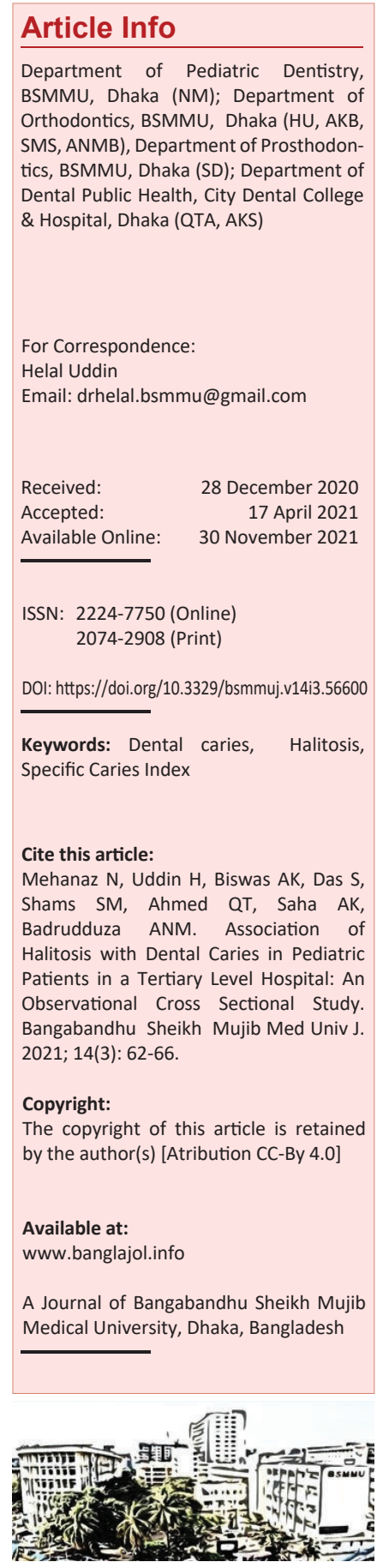

\begin{abstract}
Halitosis refers to bad breath is induced by volatile molecules due to pathological or non-pathological factors, prevalent in all ages. It can originate from either oral or non-oral sources. However, dental hygiene, periodontal disease, impacted food, tongue coat, and caries are among the oral-related sources, accounting for $90 \%$ of cases of halitosis. Therefore, this study aimed to evaluate the association between halitosis and caries among pediatric patients. This cross-sectional descriptive study documented clinical data from 45 pediatric patients at Bangabandhu Sheikh Mujib Medical University (BSMMU). The selected patients were evaluated with the Specific Caries Index (SCI) to detect the caries involvement. A halimeter was used to evaluate halitosis. According to halimeter, the mean value of halitosis in relation to sex was $169.58 \mathrm{ppb}$, while participants with very strong halitosis were observed in $12.5 \%$ of males and $33.3 \%$ of females. Patients over the age of 13 manifested extreme halitosis than other selected age groups. The result demonstrated that halitosis increased significantly with a higher score of the caries index. Hence, this study indicated an association between halitosis and the caries index in pediatric patients, highlighting the need for more research to assess its applicability in broader and diverse groups
\end{abstract}

\section{Introduction}

Halitosis refers to bad or foul breath, breath malodor, oral malodor, and foetor oris, which is commonly caused by periodontal diseases and /or tongue coating. Patients with periodontitis are prone to have halitosis than healthy people. ${ }^{1,2}$ After caries and periodontal disease, halitosis is the third most common cause for seeking dental care. ${ }^{3}$ According to reports, the prevalence of halitosis in the general population ranges from $22 \%$ to $50 \%$ around the world. ${ }^{4}$ Halitosis is thought to have an adverse impact on social communication among the general population and affects an individual's life having halitosis. Hence, it may be the source of concern for a potential health problem and frequent psychological changes that lead to social and personal isolation.

Oral causes are found to be responsible for halitosis in roughly 80-90 percent of individuals., 5 Periodontal diseases, tongue coating, peri-implant diseases, deep carious lesions, exposed necrotic tooth pulp, pericoronitis, mucosal ulcerations, impacted food, unclean dentures, and factors causing decreased salivary flow rate are among the causes that contribute to oral halitosis. ${ }^{3,7}$ It is induced by bacterial metabolism on the tongue dorsum and in periodontal pockets and the microbial breakdown of organic substrates in saliva, gingival crevicular fluids, oral soft tissues, and retained debris. ${ }^{8,9}$

According to the previous study, poor dental hygiene was found to be the source of bad breath in over 85 percent of halitosis cases, 43 percent on tongue coating, 11 percent from gingivitis and/or periodontitis, and 18 percent from a combination of the two. In 16 percent of the cases, pseudo-halitosis or halitophobia was discovered. ${ }^{10,11}$ In addition, halitosis can be a symptom of systemic diseases such as the upper and lower respiratory tract infections, metabolic diseases, carcinoma, and other systemic diseases such as diabetes mellitus that produces ketone bodies (ketoacidosis) in the breath.$^{12,13}$

Halitosis most often results from the microbial degradation of oral organic substrates, 
including volatile sulfur compounds (VSCs), including hydrogen sulfide $(\mathrm{H} 2 \mathrm{~S})$, methyl mercaptan $(\mathrm{CH} 3 \mathrm{SH})$, and other compounds. ${ }^{14}$ These compounds are produced by the proteolytic breakdown of diverse sulfur-containing substrates in food debris, saliva, blood, and epithelial cells by primarily anaerobic Gram-negative oral microbes. ${ }^{15}$ Sulfur-containing amino acids like cysteine, cystine, and methionine found in saliva or gingival fluid serve as substrates for forming volatile sulfide molecules. ${ }^{16}$ The presence of specific microbes in gingivitis and periodontitis lesions has been considered to be related to the production of high amounts of these volatile sulfur compounds. ${ }^{15}$ Breath can eventually smell like rotten eggs or filthy socks due to volatile sulfur compounds (VSCs).

Halitosis can now be measured with a halimeter. ${ }^{17}$ The halimeter is a device of gas analysis that determines how many sulfur bonds are present in a given volume of gas. It is feasible to directly measure the quantitative levels of offending VSCs present in parts per billion (ppb) using the halimeter. ${ }^{17}$ The usual range of normal breath is 80 to $160 \mathrm{ppb}$; however, unpleasant breath is expected when the halimeter readings surpass $160 \mathrm{ppb}$.

However, dental caries, a frequent chronic and multifactorial disease among children ${ }^{18}$, mainly caused by acid production occurring from bacterial fermentation by the carbohydrate and sugary foods ${ }^{19}$, are closely related to various oral health issues and have an effect on halitosis. ${ }^{7}$ Therefore, dental Caries can be evaluated with several scales, especially with specific caries index (SCI).

Many attempts have been made to discover an association between dental caries and halitosis in adult and pediatric patients. However, this relationship has so far remained contentious. Therefore, this study aimed to evaluate the relation between halitosis and the specific caries index among pediatric patients.

\section{Methods}

\section{Study Design and Participants}

Participants were recruited from the Department of Pedodontics at Bangabandhu Sheikh Mujib Medical University (BSMMU) in Dhaka, Bangladesh, for this study. Written consents were obtained from the parents/legal guardians of the pediatric patients after a thorough briefing on the purpose and aim of the study. The selected participants were free from any systemic diseases or intraoral causes that might affect the oral breath except dental caries. Patients who had taken antibiotics within the last six weeks were also not considered. 45 pediatric participants were selected to detect the association between halitosis and caries for this study.

\section{Halitosis Assessment}

According to the previous study ${ }^{7}$, halitosis values were set into four categories and classified as: normal values from
0-100 parts per billion (ppb)], weak (101-150 ppb), strong (151-300 ppb), or very strong (>300 ppb). Halitosis was measured using a VSC detector device termed 'Halimeter®' (Interscan, Chatsworth, CA, USA). Prior to measurement, each participant was asked to keep the mouth closed for 60 seconds. Then, a disposable plastic straw was placed above the posterior portion of the tongue dorsum without touching the oral mucosa or the tongue. During measurement, the mouth was kept open by approximately $1.5 \mathrm{~cm}$, and breathing was not permitted. The peak value was recorded. After duplicating the data, the mean value in parts per billion ( $p p b$ ) was determined.

\section{Caries Assessment by Specific Caries Index (SCI)}

Specific Caries Index (SCI) aimed to develop a repeatable, surface-specific caries index that would provide qualitative and quantitative information about untreated dental caries in an individual based on clinical examination. In addition, it would provide useful data for planning oral health care for a target population used in conjunction with the Decayed, Missing, and Filled Teeth (DMFT) Index. (Table -I)

\section{Statistical analysis:}

Statistical analysis was performed with the IBM mainframe version of SAS (Statistical Analysis System) utilizing the chi-square distribution, and the significance value was set at $<0.05$.

\begin{tabular}{|l|l|}
\hline Score & Criteria \\
\hline 0 & No caries lesion detected \\
\hline 1 & $\begin{array}{l}\text { Caries lesion occurring on the occlusal, buccal pits } \\
\text { and fissures of molars and premolars and the } \\
\text { lingual pits of the anterior teeth }\end{array}$ \\
\hline 2 & $\begin{array}{l}\text { Proximal caries affecting the molars and premolars } \\
\text { Caries lesion situated on the proximal surface of the } \\
\text { anterior teeth and not involving the incisal angle }\end{array}$ \\
\hline 4 & $\begin{array}{l}\text { Caries lesion situated on the proximal surface of the } \\
\text { anterior teeth and involving the incisal angle }\end{array}$ \\
\hline 5 & $\begin{array}{l}\text { Caries lesion situated on the cervical region of the } \\
\text { tooth }\end{array}$ \\
\hline 6 & $\begin{array}{l}\text { Caries lesion situated on the occlusal cusp tips of } \\
\text { molars and premolars and on the incisal edges of } \\
\text { incisors }\end{array}$ \\
\hline $6 \mathrm{~A}$ & $\begin{array}{l}\text { Grossly decayed tooth/root stumps indicated for } \\
\text { extraction }\end{array}$ \\
\hline
\end{tabular}

\section{Results}

This cross-sectional study consisted of 45 children, where $63 \%$ were male and $37 \%$ were female. The participants belonged to thre age groups i.e. 6-9, 10-13, and 14-18 years. The majority $(37.7 \%)$ of participants were from the age group of $14-18$ years. 


\begin{tabular}{|c|c|c|c|c|c|c|c|c|}
\hline \multicolumn{9}{|c|}{ Table-I } \\
\hline \multicolumn{9}{|c|}{ Distribution of the participants according to demographic profile } \\
\hline \multirow{2}{*}{\multicolumn{2}{|c|}{ Demographic profile }} & \multicolumn{4}{|c|}{ Halitosis } & \multirow{2}{*}{$\begin{array}{l}\text { Mean } \\
(\mathrm{ppb})\end{array}$} & \multirow{2}{*}{$\begin{array}{c}\text { Std } \\
\text { deviation }\end{array}$} & \multirow[t]{2}{*}{ Total $(\%)$} \\
\hline & & Normal (\%) & Weak (\%) & Strong (\%) & Very strong (\%) & & & \\
\hline \multirow[t]{2}{*}{ Sex } & Male & $5(20.8)$ & $1(4.2)$ & $15(62.5)$ & $3(12.5)$ & \multirow{2}{*}{169.58} & \multirow{2}{*}{ \pm 74.73} & $24(53.45)$ \\
\hline & Female & $0(0)$ & $6(28.6)$ & $8(38.1)$ & $7(33.3)$ & & & $21(46.55)$ \\
\hline \multirow[t]{3}{*}{ Age } & $6-9$ & $3(25.0)$ & $1(8.3)$ & $8(66.7)$ & $0(0.0))$ & \multirow{3}{*}{163.80} & \multirow{3}{*}{ \pm 74.29} & $12(26.7)$ \\
\hline & $10-13$ & $1(6.3)$ & $3(18.8)$ & $8(50.0)$ & $4(25.0)$ & & & $16(35.6)$ \\
\hline & $14-18$ & $1(5.9)$ & 3 (17.6) & 7 (41.2) & $6(35.5)$ & & & $17(37.7)$ \\
\hline \multirow[t]{2}{*}{ Residence } & Urban & $4(13.8)$ & $5(17.2)$ & $16(55.2)$ & $4(13.8)$ & \multirow{2}{*}{185.78} & \multirow{2}{*}{ \pm 78.42} & $29(64.4)$ \\
\hline & Village & $1(6.3)$ & $2(12.5)$ & $7(43.8)$ & $6(37.5)$ & & & $16(35.6)$ \\
\hline
\end{tabular}

Most of the participants (64.4\%) of this study were from urban area. According to halimeter indicator, $62.5 \%$ male participants had strong halitosis while $12.5 \%$ had very strong halitosis. The female participants of $38.1 \%$ showed strong halitosis and $33.3 \%$ were found with very strong halitosis. According to halimeter, the mean value in the perspective of sex was $169.58 \mathrm{ppb}$ while the standard deviation was \pm 74.73 ppb. Among the 10-13 years participants, 50\% had strong halitosis, and $25 \%$ had very strong halitosis. On the contrary, the age group of 14-18 years manifested strong halitosis in $41.2 \%$ of participants, while very strong halitosis was detected in $35.5 \%$. (Table-II)

Table-II

Distribution of the participants according to demographic profile( $N=45)$

\begin{tabular}{|c|c|c|c|c|c|c|c|c|c|}
\hline \multirow{2}{*}{\multicolumn{2}{|c|}{ Caries Index }} & \multicolumn{4}{|c|}{ Halitosis } & \multirow{2}{*}{$\begin{array}{l}\text { Mean } \\
(\mathrm{ppb})\end{array}$} & \multirow{2}{*}{$\begin{array}{c}\text { Std } \\
\text { deviation }\end{array}$} & \multirow[t]{2}{*}{ Total } & \multirow{2}{*}{$\begin{array}{c}P \\
\text { value }\end{array}$} \\
\hline & & Normal (\%) & Weak (\%) & Strong $(\%)$ & Very strong $(\%)$ & & & & \\
\hline \multirow[t]{8}{*}{ Score } & 0 & $1(50)$ & $1(50)$ & $0(0)$ & $0(0)$ & \multirow{8}{*}{224.911} & \multirow{8}{*}{ \pm 85.88} & 2 & \multirow{8}{*}{$<.00001$} \\
\hline & 1 & $2(66.7)$ & $1(33.3)$ & $0(0)$ & $0(0)$ & & & 3 & \\
\hline & 2 & 1 (16.7) & 1 (16.7) & $3(50)$ & 1 (16.7) & & & 6 & \\
\hline & 3 & $0(0)$ & $1(20)$ & $3(40)$ & $1(20)$ & & & 5 & \\
\hline & 4 & $1(14.2)$ & $2(28.6)$ & $2(28.6)$ & $2(28.6)$ & & & 7 & \\
\hline & 5 & $0(0)$ & $0(0)$ & $6(75)$ & $2(25)$ & & & 8 & \\
\hline & 6 & $0(0)$ & 1 (11.1) & $5(55.6)$ & $3(33.4)$ & & & 9 & \\
\hline & $6 \mathrm{~A}$ & $0(0)$ & $0(0)$ & $4(80)$ & $1(20)$ & & & 5 & \\
\hline
\end{tabular}

The result is significant at $\mathrm{p}<.05$

Halitosis Based on Caries Index

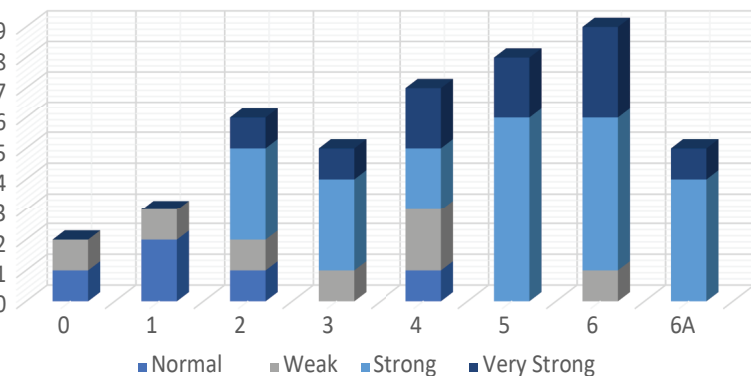

Figure-1: Prevalence of the halitosis according to specific caries index score
The Specific Caries Index by Acharya ${ }^{20}$ (SCI) was applied to the participants to detect caries status. Halitosis was measured according to halimeter. The score 0 indicated "No caries lesion detected" where halitosis was found as normal (50\%) and weak $(50 \%)$. However, in score $5,75 \%$ of the participants had strong halitosis, whereas $25 \%$ had very strong halitosis. Strong halitosis was found in $56 \%$ of the participants in the score 6 . Halitosis score (ppb) demonstrated an increasing pattern with the advancement of the caries index. The $p$ value in this bivariate study was .00001 (Table-III), which was statistically significant. It revealed that halitosis increased with caries index score (Figure-1). 


\section{Discussion}

Halitosis is a highly frequent condition that can cause major social and psychological problems. Inflammation of gingival and periodontal tissues produces common sources of oral malodors, and plaque-related periodontal disease can worsen halitosis. Periodontal pockets, dental cavities, stomatitis, rhinitis, pharyngitis, and local variables such as a lack of self-clearing agents, smoking, and food debris have all been implicated.1,2 Furthermore, dental caries a chronic and multifactorial disease, mainly caused by acid production occurring from bacterial fermentation of food ${ }^{18}$, are closely related to various oral health issues and have an effect on halitosis. $^{7}$

In the current study, 53.45 percent of the participants were male, and 46.55 percent were female. A previous study reported that most of the study population $(62 \%)$ came from the urban area. ${ }^{2}$ In contrast, 64.4 percent came from the urban area in our study, and 35.6 percent came from the village. However, severe halitosis was reported in village individuals compared to urban participants. Among the 10-13 years participants, $25 \%$ had extreme halitosis. On the contrary, the age group of $14-18$ years manifested strong halitosis in $35.5 \%$. This finding is consistent with previous research that found an increase in the prevalence of halitosis with increasing age. $^{21}$

Caries is considered to be a common source for halitosis among the oral causes. The present study was performed with a specific aim to detect the prevalence of halitosis with the caries index. The participants with halitosis were examined by the SCI. ${ }^{20}$ The halitosis score was detected with an elevated pattern in the advanced caries index that supported our hypothesis. Furthermore, another similar study ${ }^{22}$ also found that the prevalence of halitosis and the advancement of dental caries were correlated in the different age groups ranging from 10-78 years old. The result of a previous study with a separate index was also associated with this study's findings that demonstrated higher halitosis occurrence with a higher caries index score. ${ }^{1}$ The possible explanation is that caries is usually caused by acid production from bacterial fermentation of food responsible for producing volatile sulfur compounds (VSC) that account for halitosis. ${ }^{23}$ The more bacterial fermentation produces more sulfur compounds, so does halitosis.

According to our findings, the consequences of dental caries may explain the occurrence of halitosis and suggest that more research be conducted to understand the molecular pathway of halitosis and other oral causes across a broad spectrum.

\section{Conclusion}

The present study proved the relationship of halitosis with the dental caries inpediatric patients only. This study found strong evidences that halitosis is directly related to dental caries and its severity according to caries index among the paedietric patients attending the OPD of BSMMU. Further broad scale studies are needed to conclude such relationship.
Funding support: Self-funded.

Conflict of interest: The authors declare no conflict of interest.

\section{References}

1. Apatzidou A, Bakirtzoglou E, Vouros I, Karagiannis V, Papa A, Konstantinidis A. Association between oral malodour and periodontal disease-related parameters in the general population. Acta Odontologica Scandinavica. 2013;71(1):189-95.

2. Van den Broek AM, Feenstra L, de Baat C. A review of the current literature on aetiology and measurement methods of halitosis. Journal of dentistry. 2007;35(8):627-35.

3. Al-Zahrani MS, Zawawi KH, Austah ON, Al-Ghamdi HS. Self reported halitosis in relation to glycated hemoglobin level in diabetic patients. The open dentistry journal. 2011;5:154.

4. Lu HX, Tang C, Chen X, Wong M, Ye W. Characteristics of patients complaining of halitosis and factors associated with halitosis. Oral diseases. 2014;20(8):787-95.

5. Delanghe G, Ghyselen J, Feenstra L, van Steenberghe D. Experiences of a Belgian multidisciplinary breath odour clinic. Acta oto-rhino-laryngologica Belgica. 1997;51(1): 43-8.

6. Miyazaki H, Sakao S, Katoh Y, Takehara T. Correlation between volatile sulphur compounds and certain oral health measurements in the general population. Journal of periodontology. 1995;66(8):679-84.

7. Eid HA. Non surgical management of periodontitis related halitosis among adults. Saudi Journal for Health Sciences. 2014;3(2):80.

8. Donaldson A, McKenzie D, Riggio M, Hodge P, Rolph H, Flanagan A, et al. Microbiological culture analysis of the tongue anaerobic microflora in subjects with and without halitosis. Oral diseases. 2005;11:61-3.

9. Rosenberg M. First international workshop on oral malodor. Journal of dental research. 1994;73(3):586-9.

10. Chomyszyn-Gajewska M, Skrzypek A. Halitosis-diagnosis and treatment. Przeglad lekarski. 2013;70(2): 65-8.

11. Quirynen M, Dadamio J, Van den Velde S, De Smit M, Dekeyser C, Van Tornout M, et al. Characteristics of 2000 patients who visited a halitosis clinic. Journal of clinical periodontology. 2009;36(11):970-5.

12. Pratibha P, Bhat G. Oral malodor: a review of the literature. American Dental Hygienists' Association. 2006;80(3):8. 
13. Southward K, Bosy A. Treatment of oral malodor and periodontal disease using an antibiotic rinse. General dentistry. 2013;61(4):41-5.

14. Goldberg S, Kozlovsky A, Gordon D, Gelernter I, Sintov A, Rosenberg M. Cadaverine as a putative component of oral malodor. Journal of dental research. 1994;73(6):1168-72.

15. Tonzetich J. Production and origin of oral malodor: a review of mechanisms and methods of analysis. Journal of periodontology. 1977;48(1):13-20.

16. Quirynen M, Zhao H, Soers C, Dekeyser C, Pauwels M, Coucke $\mathrm{W}$, et al. The impact of periodontal therapy and the adjunctive effect of antiseptics on breath odor-related outcome variables: a double-blind randomized study. Journal of periodontology. 2005;76(5):705-12.

17. Salako NO, Philip L. Comparison of the use of the Halimeter and the Oral Chroma ${ }^{\mathrm{TM}}$ in the assessment of the ability of common cultivable oral anaerobic bacteria to produce malodorous volatile sulfur compounds from cysteine and methionine. Medical Principles and Practice. 2011;20(1):75-9.
18. Edelstein BL, Douglass CW. Dispelling the myth that 50 percent of US schoolchildren have never had a cavity. Public health reports. 1995;110(5):522.

19. Benson PE, Douglas CI, Martin MV. Fluoridated elastomers: effect on the microbiology of plaque. American journal of orthodontics and dentofacial orthopedics. 2004; 126(3):325-30.

20. Acharya S. Specific caries index: A new system for describing untreated dental caries experience in developing countries. Journal of public health dentistry. 2006;66(4):285-7.

21. Nadanovsky P, Carvalho L, Ponce de Leon A. Oral malodour and its association with age and sex in a general population in Brazil. Oral diseases. 2007;13(1):105-9.

22. Suzuki N, Yoneda M, Naito T, Iwamoto T, Hirofuji T. Relationship between halitosis and psychologic status. Oral Surgery, Oral Medicine, Oral Pathology, Oral Radiology, and Endodontology. 2008;106(4):542-7.

23. DE BOEVER EH, Loesche WJ. Assessing the contribution of anaerobic microflora of the tongue to oral malodor. The Journal of the American Dental Association. 1995;126(10): 1384-93. 